Corrigendum

\title{
Corrigendum to "Improving the Color Stability of Naturally Colored Silk by Cross-Linking the Sericin with Phytic Acid"
}

\author{
Mingbo Ma $\mathbb{D}^{1},{ }^{1}$ Pirah Ayaz, ${ }^{1}$ Wanhui Jin, ${ }^{2}$ and Wenlong Zhou $\mathbb{D D}^{1}$ \\ ${ }^{1}$ Department of Textile and Materials, Zhejiang Sci-Tech University, Hangzhou 310018, China \\ ${ }^{2}$ Hubei Province Fibre Inspection Bureau, Wuhan 430000, China \\ Correspondence should be addressed to Wenlong Zhou; wzhou@zstu.edu.cn \\ Received 9 June 2019; Accepted 18 June 2019; Published 10 October 2020 \\ Copyright (c) 2020 Mingbo Ma et al. This is an open access article distributed under the Creative Commons Attribution License, \\ which permits unrestricted use, distribution, and reproduction in any medium, provided the original work is properly cited.
}

In the article titled "Improving the Color Stability of Naturally Colored Silk by Cross-Linking the Sericin with Phytic Acid" [1], there was an error in Figure 4, as the authors uploaded the wrong version of the figure during the production stage. It should be corrected as follows: 


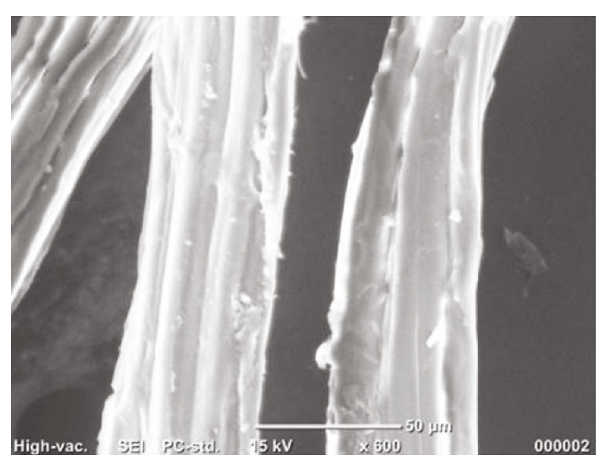

(a)

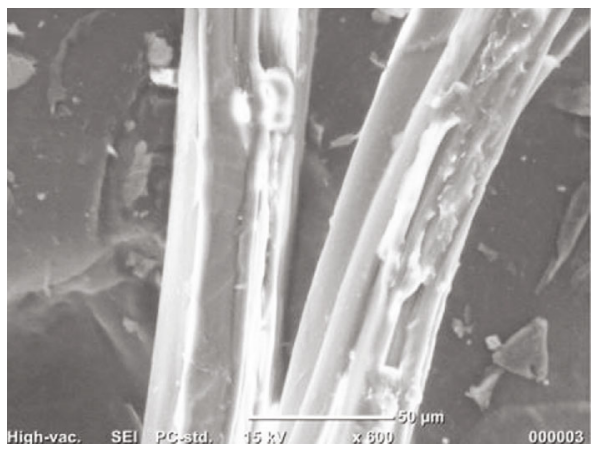

(c)

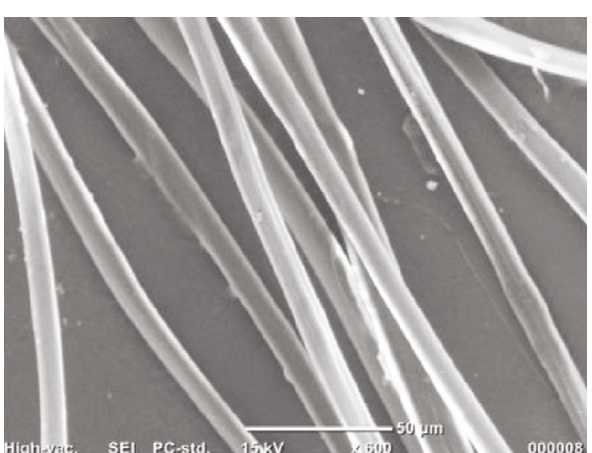

(b)

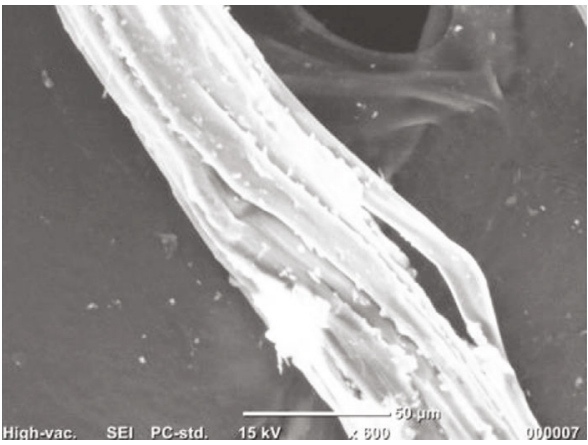

(d)

FIGURE 4: SEM observation of uncross-linked and cross-linked NCS filament before and after degumming. (a, b) Uncross-linked fiber before and after degumming; (c, d) cross-linked fiber before and after degumming.

\section{References}

[1] M. Ma, P. Ayaz, W. Jin, and W. Zhou, "Improving the color stability of naturally colored silk by cross-linking the sericin with phytic acid," International Journal of Polymer Science, vol. 2019, Article ID 6936437, 7 pages, 2019. 